\title{
Views of cancer care reviews in primary care: a qualitative study
}

\author{
Eike Adams, Mary Boulton, Peter Rose, Susi Lund, \\ Alison Richardson, Sue Wilson and Eila Watson
}

\section{ABSTRACT}

\section{Background}

The Quality and Outcomes Framework (QOF) provides an incentive for practices to establish a cancer register and conduct a review with cancer patients within 6 months of diagnosis, but implementation is unknown.

Aim

To describe: (1) implementation of the QOF cancer care review; (2) patients' experiences of primary care over the first 3 years following a cancer diagnosis; (3) patients' views on optimal care; and (4) the views of primary care professionals regarding their cancer care.

Design of study

Qualitative study using thematic analysis and a framework approach.

Setting

Six general practices in the Thames Valley area. Method

Semi-structured interviews with cancer patients and focus groups with primary care teams.

Results

Thirty-eight adults with 12 different cancer types were interviewed. Seventy-one primary care team members took part in focus groups. Most cancer care reviews are conducted opportunistically. Thirty-five patients had had a review; only two could recall this. Patients saw acknowledgement of their diagnosis and provision of general support as important and not always adequately provided. An active approach and specific review appointment would legitimise the raising of concerns. Primary care teams considered cancer care to be part of their role. GPs emphasised the importance of being able to respond to individual patients' needs and closer links with secondary care to facilitate a more involved role.

\section{Conclusion}

Patients and primary care teams believe primary care has an important role to play in cancer care. Cancer care reviews in their current format are not helpful, with considerable scope for improving practice in this area. An invitation to attend a specific appointment at the end of active treatment may aid transition from secondary care and improve satisfaction with follow-up in primary care.

Keywords

cancer; primary health care; quality indicators, health care; survivorship.

\section{INTRODUCTION}

Increased screening and earlier detection, improved treatments and survival, together with an ageing population have led to increasing numbers of cancer survivors. The Cancer Reform Strategy has highlighted the devastating impact cancer can have on the quality of patients' lives and has emphasised the need for patients, families, and carers to have access to information and support throughout the care pathway. ${ }^{1}$ While active management of cancer is primarily centred in secondary care, primary care has a key role to play in managing treatment effects and comorbidities, and in supporting the patient and their family to live with and beyond a diagnosis of cancer. ${ }^{2,3}$

Previous research has indicated that patients with cancer see an important role for primary care. ${ }^{3}$ Key times include the point of diagnosis, the end of active

E Adams, BSc, $P h D$, research fellow; M Boulton, $B A, P h D$, professor of health sociology and director of research; $\boldsymbol{E}$ Watson, $B S c, P h D, H R H$ Prince Sultan Chair in Supportive Cancer Care, Oxford Brookes, University School of Health and Social Care, Oxford. P Rose, BA, MA, MB, BChir, FRCGP, MD, clinical lecturer/GP principal, University of Oxford, Department of Primary Health Care, Oxford. S Lund, SRN, DNCert, MA, PhD, visiting research associate, nurse consultant end of life care, Royal Berkshire NHS Foundation Trust, London. A Richardson, BA, RGN, MA, PhD, Clinical Chair in Cancer Nursing and End of Life Care, Southampton General Hospital NHS Trust and the University of Southampton, Southampton. S Wilson, $B A, P h D$, professor of clinical epidemiology, Health and Population Sciences, Primary Care Clinical Sciences, University of Birmingham, Birmingham.

Address for correspondence

Professor Eila Watson, HRH Prince Sultan Chair in Supportive Cancer Care, Oxford Brookes University, School of Health and Social Care, Jack Straws Lane, Oxford OX3 OFL.

E-mail: ewatson@brookes.ac.uk

Submitted: 16 August 2010; Editor's response: 28 September 2010; final acceptance: 18 October 2010.

(C)British Journal of General Practice

This is the full-length article (published online 28 Mar 2011) of an abridged version published in print. Cite this article as: Br J Gen Pract 2011; DOI: 10.3399/bjgp11X567108. 
treatment, discharge from hospital follow-up, diagnosis of a cancer recurrence, and the terminal phase of illness. ${ }^{3,4}$ GPs see themselves as playing a role in cancer follow-up, and consider themselves wellplaced because of their accessibility and existing relationships with patients. ${ }^{5}$ However, barriers to their involvement have been recognised, such as costs, time limitations, lack of expertise, and lack of mutual confidence and communication between primary and secondary care. ${ }^{5,6}$ Research on patient views has suggested patients trust their GPs to provide competent care, ${ }^{7}$ although lack of oncological expertise is seen as a barrier to effective cancer care in primary care. ${ }^{3,8}$

The role of the primary care team in the care of people with cancer is currently not well defined. Traditionally, primary cancer care has focused on palliative care, and that aspect of practice is now well developed. The Gold Standards Framework is increasingly being used to help practices plan and deliver needs-based palliative care. ${ }^{9}$ However, there is no such guidance defining the role of primary care in supporting the much larger number of cancer patients who are not receiving palliative care and are in the diagnostic, treatment, and post-treatment phases. Since 2003, the Quality and Outcomes Framework (QOF) of the General Medical Services Contract for Primary Care has provided an incentive for practices to establish a cancer register, and to conduct a review with new patients with cancer within 6 months of diagnosis (a 'cancer care review'). ${ }^{10}$ However, it is not clear how practices have responded to these incentives, the format of reviews implemented, or how they are regarded by patients and the primary care team. Without a clear picture of these issues, it is difficult to assess the value of the QOF cancer indicators or to suggest improvements.

An important first step is therefore to describe current practice, in particular the nature and scope of the reviews, and whether or not they are perceived to be useful. A recent review of the current QOF guidance reiterated the lack of evidence informing the role of primary care in the management of cancer patients, and concluded there was no new evidence available of sufficient quality to propose substantive changes to the current indicators. ${ }^{11}$

This paper reports findings from a qualitative study aimed at describing the extent to which the QOF cancer care indicators, with a focus on the cancer care review, have been implemented in primary care; exploring patients' experiences of involvement of primary healthcare professionals in their care over the first 3 years following a cancer diagnosis; describing patients' views on the optimal role for the primary care team in the period following a cancer diagnosis; and exploring the views of primary healthcare professionals

\section{How this fits in}

A diagnosis of cancer and its treatment can be devastating to patients and their family members. Primary care has an increasing role to play in providing cancer follow-up care. The Quality and Outcomes Framework (QOF) recommends a cancer care review within 6 months of diagnosis, but no clear guidelines exist to structure this review and there is no evidence as to appropriate timing or whether there is any value to patients or health professionals in conducting a review. QOF cancer care reviews are currently not being implemented to the satisfaction of either patients or healthcare professionals. Most patients are unaware of a QOF cancer care review having taken place and would welcome greater involvement of the primary care team in cancer care, greater

acknowledgment, and the opportunity to have a designated review appointment to raise any concerns. Improved communication between secondary and

primary care and between primary care and patients has been highlighted by all participants as key to improving the quality of care.

regarding their involvement in the care of people diagnosed with cancer.

\section{METHOD}

\section{Primary care practices}

Six GP practices in the Thames Valley region were recruited to the study via the Thames Valley Primary Care Research Network. Practices were selected to include rural and urban settings and a mix of ethnic groups and levels of deprivation. All practices had a cancer register and recorded whether patients on the register had received a cancer care review.

\section{Patients}

Patients were eligible for recruitment to the study if they had been diagnosed with cancer 6-36 months before the start of the study, were 18 years or older, and were not in the terminal phase of illness as measured by eligibility for the DS1500 (a short medical report denoting terminal illness with life expectancy of less than 6 months, to claim benefits from the Department for Work and Pensions). Patients were excluded if their GP felt they may be adversely affected by an invitation to take part in the study. Patients were identified from anonymised cancer registers at each practice. Practices were asked to provide a list of all eligible patients and their date of diagnosis, cancer type, ethnicity (if available), whether or not a QOF cancer care review was recorded as having taken place, and the review date if available. The sample was stratified by time since diagnosis into three groups: 6-12 months, 13-24 months, and 25-36 months postdiagnosis. Patients were then selected using maximum variation sampling strategies ${ }^{12}$ to achieve maximum heterogeneity in the sample in relation to age, sex, ethnicity, and cancer type. Patients were recruited from each practice consecutively between March 2009 and January 2010. They were invited, by a letter from their GP, to participate in a semi-structured interview. 
Patients were also asked to invite a close family member to take part in the study. The results from interviews with family members will be reported separately.

Written consent was obtained from each participant. One non-clinician researcher who has no links with primary care teams conducted semistructured interviews with participants about their experiences of primary care involvement in cancer care, their views on potential improvements, and any needs and concerns they had and how these could best be addressed. Most patients were interviewed in their own home, with one patient choosing their local GP practice, and two others their local cancer centre. The interviews lasted a mean of 49 minutes (range 17-100 minutes) and were audiorecorded, transcribed verbatim, and analysed using framework analysis. ${ }^{13}$ Patients knew the interviewer was independent from their primary care team.

A thematic coding framework was developed by three researchers, which identified key issues within the data on the basis of the aims of the study, in addition to other issues raised by participants. Computer software was used to organise the data for analysis (NVivo 8). Initial coding was compared between the researchers to clarify and refine definitions. Codes were combined into broader

Table 1. Patient characteristics.

\begin{tabular}{|c|c|}
\hline Characteristics & $\begin{array}{l}\text { Number of patients } \\
\qquad(n=38)\end{array}$ \\
\hline \multicolumn{2}{|l|}{ Age at interview, years } \\
\hline$<50$ & 8 \\
\hline $50-70$ & 14 \\
\hline$>70$ & 16 \\
\hline \multicolumn{2}{|l|}{ Sex } \\
\hline Female & 19 \\
\hline Male & 19 \\
\hline \multicolumn{2}{|l|}{ Time since diagnosis, months } \\
\hline $6-12$ & 11 \\
\hline $13-24$ & 14 \\
\hline $25-36$ & 13 \\
\hline \multicolumn{2}{|l|}{ Cancer type } \\
\hline Breast & 9 \\
\hline Prostate & 6 \\
\hline Colorectal & 4 \\
\hline Head and neck & 4 \\
\hline Lung & 3 \\
\hline Melanoma & 3 \\
\hline Testicular & 2 \\
\hline Endometrioid/uterine/pelvic & 2 \\
\hline Hodgkin's lymphoma & 2 \\
\hline Non-Hodgkin's lymphoma & 1 \\
\hline Bladder & 1 \\
\hline Renal & 1 \\
\hline \multicolumn{2}{|l|}{ Ethnicity } \\
\hline White British & 36 \\
\hline White other & 2 \\
\hline
\end{tabular}

themes, which were discussed in the core analysis team and with the wider project team. Where participants made unusual statements that were not voiced by other participants, these were discussed and included if it was felt that they made a point that would be useful or meaningful for the wider discussion, rather than making a statement that was only relevant to their own, personal situation. Overall, points made in this paper were those that were supported by most participants. For each theme, the most suitable (succinct and clear) quotes were selected for the paper. A document detailing initial findings was developed for discussion at the focus groups. Three of the researchers were academic researchers, but data were discussed extensively with the three clinical members of the team and with the patient representatives to make sure that those findings that were most meaningful to clinical practice were emphasised.

\section{Focus groups}

All members of the primary healthcare team at each of the six practices were invited, via the lead GP or practice manager, to participate in a focus group at their practice once all patients had been interviewed.

One of the authors conducted each focus group, with the assistance of one of the other authors at four of the six groups. Focus groups took place from November to January 2010. They lasted between 30 minutes and an hour, with most focus groups being half an hour. Focus groups traditionally tend to be longer, but these focus groups had to be scheduled as part of regular practice meetings, and a longer duration could not be negotiated with most practices. They were audiorecorded, transcribed verbatim, and analysed thematically. ${ }^{13,14}$ Analysis focused on primary care team members' views on the feasibility of their involvement in cancer care and QOF cancer care reviews. Focus group transcripts were initially analysed for content in their own right, alongside the final analysis of interviews. Commonalities and differences between patients', family members', and primary care team members' views were then discussed between members of the research team to inform the overarching story reported here.

\section{RESULTS}

\section{Current delivery of QOF cancer care reviews in primary care}

A cancer care review was recorded in the medical records of 35 of the 38 patients who took part in the study. Medical records showed the review of 30 patients was conducted within 6 months of diagnosis as recommended; nine of these were conducted within the first 4 weeks after diagnosis. 


\section{Patients' experiences and views}

Practices identified 488 potentially eligible patients; 69 were excluded because they did not fit the eligibility criteria; 38 were recruited to the study. Characteristics of the patients who took part in the study are described in Table 1.

\section{Experiences of primary care involvement in cancer care}

Several patients described that they actively kept their doctor 'up to date' with their cancer care by going to see them regularly:

I'm seeing Doctor $X$ today, and she will probably have the letter from him, she may not but I will explain to her what he says, yeah I mean we always debrief on everything.' (P1, 66-year-old female)

'After any length of time, I usually book and go and tell her how it's going, you know, every 3 or 4 months, well no, not even as often as that, certainly once in 6 months I go and say "I've just come to bring you up to date", but usually there is something before that that l've had to see her for, I do feel she should be kept up to date, because if I suddenly go downhill I don't want to have to become completely briefed from scratch.'

(P74, 67-year-old male)

Other patients also perceived themselves to be the ones initiating any contact but did not do so without a direct reason, for example, side effects:

'I mean they've only been involved whenever l've been to them to ask, for example when I was having chemotherapy I got this really terrible kind of pain in my face, so I went along to them for that, so when l've had to go along for anything to do with it, or to get a repeat prescription, you know then they've been involved, but otherwise they're not really involved.' (P77, 45-year-old female)

In all of these cases, the act of involvement was initiated by the patient, rather than the primary care team.

Overall, experiences ranged from almost no involvement, and very little input from the primary care team to close and ongoing involvement:

'He hasn't been involved that much, I think sort of the first time I went back to see him he just asked me how I was, but we didn't discuss anything about the operation or anything like that, so no, not really.' (P214, 85-year-old female)
'I have to say my GP is very good, I'm in e-mail contact with him, so if I need anything I can e-mail him and he will provide what he can, for instance I had a virus in April, May, with a bad cough I couldn't get rid of it, and he did give me things that you know, he wouldn't ever give to somebody who doesn't have cancer, for instance, I asked for an $x$ ray because I was worried, he gave me the $x$-ray; now there's no doubt that he wouldn't do that with somebody who doesn't have cancer, so he is very good.' (P42, 47-year-old female)

The involvement of the primary care team in the patient's cancer care seemed mediated not only by their personal relationship, but also by the patient's proactive efforts to maintain contact, the site of the patient's cancer, the type of cancer treatment received, and what treatment the patient received from the primary care team for other conditions.

\section{Experiences of cancer care reviews}

Most patients expressed general satisfaction with their GP practice, but they did not feel their primary care team had been very involved in their cancer care. Only two of 38 patients interviewed reported having had a cancer care review; 20 patients could not recall any detailed discussion of their cancer. In total, 16 patients were in regular contact with a member of the primary care team for cancer-related issues (such as hormone injections for prostate cancer or monitoring of other cancer-related medication) or the management of other chronic health conditions, but although most of them felt that they could have initiated a discussion of concerns associated with their cancer diagnosis, they were not actively asked by healthcare professionals about their cancer and how they felt:

'There's one doctor and I always see the same nurse, as I say I don't expect them to sort of go "how are you after your lymphoma?", but I get the impression they don't even, they're not even aware of it, so some sort of follow-up thing would be nice because there are things you'd like to ask because when you do come back here for your 6 monthly check up they're so pushed for time.' (P52, 74-year-old male)

The two patients who reported having had a cancer care review described it as having limited value:

'They invited us to go and see them as a follow-up, but she was not aware of the operation I'd actually had, and she was not aware what they had in fact done, and she, sitting discussing with her "they really do that now do they?", so it wasn't as if we 
could go up there and sort of seek advice and help, it was quite a big gap really.' (P20, 68-year old male)

'He hadn't looked at the notes, it was almost like I kind of went through "this is what I've got, these are the drugs I'm having", which was ... Trying to remember all those, so it wasn't really, there was no value to me at all at that point frankly, it was a bit of a waste of time quite honestly.' (P16, 36year-old male)

\section{Views on the optimal role of primary care}

Patients did express some uncertainty over the role that primary care could play in their clinical cancer care. They were unsure whether their primary care team would have the necessary expertise:

'I wouldn't ring the GP because I would think well, he's not really going to know, you know, he's not really going to be able to help me because he's not a specialist in that area, so you know if I get sort of aches and pains that I'm worried about, and I'm thinking oh gosh, you know, what's going on there, is there something, some problem, I'll always ring my breast care nurse about that.' (P215, 39-year-old female)

'I mean, the GP won't give as detailed, I mean she can only talk in terms of broad facts, because that's all she can do, she's not a specialist, so you're not going to get chapter and verse unless you see a specialist.' (P94, 63-year-old male)

However, most patients also saw it as important that their GP acknowledged their cancer diagnosis and treatment, which could be part of a cancer care review. This would give reassurance that their primary care team knew of, and cared about, what this meant to the patient:

'It might acknowledge the fact l've been ill, it would be nice to have some acknowledgement.' (P19, 45-year-old male)

I think perhaps, just somebody from the surgery saying, you know, we are here and we sympathise ... I think I could have done with someone just to confirm that I'm a person and you know, a little bit of sympathy goes a long way.' (P230, 56-year-old female)

The majority of patients felt that a designated appointment to discuss their cancer care would be useful as it could provide a legitimate context for reviewing their experience and raising any concerns:
'I think that would be a good idea and I think it should be a separate appointment, because it's too easy just to say "are you OK?", and I'm one of those people that goes along and says "yes, I'm fine", whereas if you're given an actual appointment where you know that it's for you to say what you feel, it's possibly a much better outlet.' (P230, 56-year-old female)

'Having a contact, doesn't have to be that frequent but some sort of pattern of contact with the surgery that you didn't have to, because you're feeling well, you're not, as I said you're not perhaps pushy enough to get somebody who will come to you and ask.' (P202, 63-year-old female)

Most patients saw the end of active treatment as the most useful time for an initial review with their GP, which would often be at the end or even beyond the current QOF target of a review within 6 months of diagnosis. Others saw the initial phases as the optimal time for review, or preferred to have several reviews during their cancer journey.

However, the vast majority of patients, even those who had regular contact with the practice, would have welcomed a call or other proactive contact from the practice, at the time of diagnosis or initial treatment (surgery):

'Would have been nice either a call or offered me an appointment to come in, I think I would rather have the invitation, because sometimes people think they're too busy, you don't want to bother them, but you don't know yourself what you want and what you don't want.' (P204, 57-year-old female)

'Sort of had this nice idea of maybe the nurse from down there popping round, you've just had major surgery, let's pop in and see you, that would be quite nice, something like that aftercare wise would be nice.' (P19, 45-year-old male)

It seems that an active approach by the primary care team would remove some of the patients' anxieties over whether their concerns are legitimate and warrant a consultation, and whether their primary care team is the right care provider to consult.

Patients mentioned various topics they would like to be covered if a review appointment were offered, including acknowledgement of the illness, emotional support, and reassurance; information, or signposting to information, about treatment options, side effects, and possible long term-effects of their treatments, and potential symptoms of recurrence; financial support, travel insurance, disability living allowance, and 
attendance allowance; peer support and local support groups; medication review; and formal counselling and psychological support. Other issues that were mentioned included explaining cancer in lay terms, palliative care, and support for children.

However, patients were also concerned about what they perceived as barriers to consistent primary care involvement. There was a perception that a lack of coordination between primary care and secondary care hampered continuity of care:

'I fear that there's no consistency between specialists and GPs, because I like to feel as though I trust my GP, but when they start bickering about "oh your GP doesn't know anything", you can be easily swayed, and you say "should I be talking to my GP about this?".' (37year-old male)

Patients were very aware of time pressures on their GPs and were unsure how they would have the time needed to conduct a cancer care review within the normal consultation:

'They don't have time, I mean I don't know how much time they're meant to spend on you ... you know, you see the people outside and you know that they've got, I don't know whether it's 7 or 10 minutes, but you can feel the pressure on you all the time.' (P74, 67-year-old male)

'Some sort of follow-up thing would be nice because there are things you'd like to ask because when you do come back here for your check up they're so pushed for time, you haven't, they obviously haven't really got a lot of time.' (P52, 74-year-old male)

This awareness of pressures on staff stopped many patients from raising their concerns about their cancer with their GP or nurse.

\section{Primary care teams' current practice and views}

Seventy-one individuals from six primary care practices participated in focus groups conducted at each of the participating practices. Individuals' characteristics are described in Table 2. Although nursing and administrative staff attended the focus groups, GPs were by far the most vocal professional group during discussions. Overall, consensus in the discussions was high and practices presented a fairly united front in the focus groups.

Some disagreement between different members of the primary care team was evident in relation to discussions about maintaining patient confidentiality
Table 2. Practice characteristics and professions of focus group participants.

\begin{tabular}{|c|c|c|}
\hline $\begin{array}{l}\text { Practice } \\
\text { number }\end{array}$ & Description & $\begin{array}{l}\text { Focus group } \\
\text { participants }\end{array}$ \\
\hline 1 & $\begin{array}{l}\text { Rural; mixed population in terms of } \\
\text { socioeconomic background, age, and ethnicity }\end{array}$ & 5 GPs, 1 PM, 1 deputy PM \\
\hline 2 & $\begin{array}{l}\text { Rural to suburban; mainly affluent; many young } \\
\text { families }\end{array}$ & $\begin{array}{l}10 \mathrm{GPs}, 7 \mathrm{PNs}, 1 \mathrm{PM} \text {, } \\
1 \text { admin, } 1 \mathrm{HCA}\end{array}$ \\
\hline 3 & $\begin{array}{l}\text { Suburban; mainly affluent; few ethnic minority } \\
\text { patients; many young families }\end{array}$ & $\begin{array}{l}5 \text { GPs, } 2 \text { PNs, } \\
1 \text { phlebotomist + HCA, } \\
1 \text { PM, } 2 \text { receptionists, } \\
1 \text { secretary, }\end{array}$ \\
\hline 4 & $\begin{array}{l}\text { Urban; deprived area; high percentage of } \\
\text { ethnic minority patients }\end{array}$ & $\begin{array}{l}2 \mathrm{GPs}, 1 \mathrm{PN}, 1 \mathrm{PM}, \\
4 \text { receptionists }\end{array}$ \\
\hline 5 & $\begin{array}{l}\text { Urban; deprived area; high percentage of } \\
\text { ethnic minority patients }\end{array}$ & $\begin{array}{l}3 \text { GPs, } 1 \text { PN, } 1 \text { PM, } \\
2 \text { admin }\end{array}$ \\
\hline 6 & $\begin{array}{l}\text { Suburban; mixed population in terms of } \\
\text { socioeconomic background; few ethnic } \\
\text { minority patients }\end{array}$ & $\begin{array}{l}6 \text { GPs, } 1 \text { GP trainee, } \\
1 \text { medical student, } 2 \text { PNs, } \\
2 \text { DNs, } 1 \text { PM, } 4 \text { admin }\end{array}$ \\
\hline Total & & $\begin{array}{l}31 \text { GPs, } 1 \text { GP trainee, } \\
1 \text { medical student, } 13 \text { PNs, } \\
2 \text { DNs, } 6 \text { PMs, } \\
1 \text { phlebotomist, } 1 \mathrm{HCA} \text {, } \\
15 \text { admin }\end{array}$ \\
\hline
\end{tabular}

Admin = member of administrative staff. $D N=$ district nurse. $H C A=$ healthcare assistant. $P M=$ practice manager. $P N=$ practice nurse.

and involving the family, and also with regard to the level of involvement of primary care in cancer care in general.

However, the focus in this paper is on responses to patient findings, and discussions of the dynamics within each group go beyond the scope of this paper.

\section{Views on the role of the primary care team in} cancer care

The vast majority of participants saw supporting cancer patients as part of their role, and as something they wanted to be involved in:

'I think this is something we all feel, that we make time for, you know, and this is, as GPs we feel we should be very closely involved in these patients.' (practice 6, GP partner)

'I think the supportive role, which can be played in primary care, because the focus I think of secondary care is so much on the treatment a lot of the time, I think there is a real place for the offer of supportive role, I think there's a very real role for that in the community, and I think it's an ongoing one really, and it doesn't have to fit in to the review, though it can do.' (practice 1, GP partner)

Only a small minority of GPs felt the role of primary care in cancer care should mainly be during the 
palliative phase and were dismissive of the role of information provision, and more general supportive care altogether:

'We're not an information service for everything under the sun, you want that stuff you go to the $C A B$ [citizens' advice bureau] ... we don't have the time, we can't fit people in just for willy-nilly appointments to give them a little pat on the back.' (practice 5, GP partner)

\section{Current practices regarding QOF cancer care reviews}

Current procedures for the cancer care review varied from practice to practice, and also between GPs within the same practice. GPs from three practices reported they would normally telephone the patient when they received confirmation of diagnosis from secondary care, but patients were not necessarily invited to a cancer care review appointment. GPs at the other practices did not necessarily telephone the patient in every case, but did so in special cases. Whether they remained involved in delivering cancerspecific care to the patient was dependent on a number of factors: the cancer type and treatments received, the general health of the patient, the level of involvement with secondary care, and the previous relationship with the patient:

'Personally speaking it's completely ad hoc, depends on the situation, sometimes you refer someone you don't actually hardly see them for 6 months, because they have the operations, the chemotherapy, next thing you know it's months later and you get a letter, I mean personally I generally write to the patient or phone them, or when I next see them ...' (practice 1, GP partner)

Cancer care reviews were largely conducted opportunistically, either in person or over the phone.

Most GPs viewed the current QOF cancer care review template unfavourably. They saw it largely as a tick-box exercise and felt that although templates in general may be useful as aide-mémoires, the current cancer care review template was insufficient:

'I don't think it's of any value personally, I don't think it's to the patient benefit at all, I think it's just another hoop you have to jump through if you want to get paid.' (practice 5, GP partner)

I find that the box for the cancer really, the QOF for the cancer, is really needless and I think, you know, the doctors were doing this anyway, and I don't think it's been of any benefit at all, in practice.' (practice 3, GP partner)

\section{Views on future delivery of cancer care}

Most participants saw individualised and personally tailored care as extremely important and some saw too much structure as a threat to their provision of this individualised care:

'I'd say there's a balance, I feel personally there's a balance between having a template with everything there, when you can be very easy just to tick all the boxes, versus seeing the patient that walks in.' (practice 6, GP partner)

'I do have slight anxieties about making everything so structured, I mean the ethos has always been "we're accessible, we're here if you want us, if you do come in we don't have to follow a template, we can go by your agenda, and what you're worried about", and I have concerns about templates.' (practice 2, GP partner)

Focus group participants discussed the difficulty of knowing when the optimal time would be to offer patients a cancer care review:

'It's difficult I think to produce a schedule, where you say "we'll see every cancer patient a month after the diagnosis" or something because they'd be involved in other things, some will still be in hospital having surgery possibly, some will be having radiotherapy, chemotherapy, all sorts of other things going on, and it's quite difficult to sort of, you're going to have lots and lots of pathways and it's difficult to find the appropriate time.' (practice 3, GP partner)

Most focus group participants favoured an 'open door policy' - not inviting patients in for a specific appointment but making sure they were aware they could come in at any time:

'We may not see them for several weeks and months until things start progressing, because often the patient's got so much time going backwards and forwards to the hospital they kind of get a bit fed up with the whole thing, but I think it's just making sure that they know that they can contact us, but what you don't want to be doing is knocking on their door, making them feel that you're wanting to see them all the time, and they actually might not want you.' (practice 1, GP partner)

Most GPs were under the impression that this 'opendoor policy' would be sufficient to facilitate contact for the patients.

However, reflecting on the findings that many 
patients said they would welcome a specific review appointment, most primary care teams seemed open to the possibility of changing practice:

'I mean that's why the whole idea to improve the patient care, if the patient is looking for the specific review, I don't think that we have any problems with that.' (practice 4, GP partner)

'It would be interesting to go back to this point of whether we should actually call these patients in, they may want to come in, they may not want to come in, but whether we should actually call them all in, at a certain time once they've got a diagnosis of cancer, to discuss it, at least we can go through all the things, and things they may not be happy with, whether they're frightened, and if they need follow-up, follow them up and if they don't want follow-up then that's fine.' (practice 3, GP partner)

Focus group participants expressed concerns about their ability to cover all of the issues raised as important by patients, because of both time pressures and lack of expertise:

'One of the things really struck me was the patients really wanted a lot of information, and to some extent I think the sort of cancer care review process is probably not the place for that, I mean I think a few good websites and information sheets or a few helplines for the patients, they could actually be more useful, I think you could do a lot of that outside of a GP setting, if there was more sort of an information infrastructure that would be helpful.' (practice 3, GP partner)

'I also feel you know, I probably don't know enough about the subject to give advice, but I think from an emotional point of view, yeah, you just sometimes you just have to listen, don't you.' (practice 5, practice nurse)

Participants were also concerned about their ability to keep abreast of developments in cancer treatments, and what they perceived to be insufficient communication with secondary care:

'So it's the initial diagnosis, that I think generally now the information is excellent, but I think at 6 months or something, often the information isn't as good, and that was I think what I read quickly, where the patients were wanting their review with us, more formal review.' (practice 2, GP partner)

One GP participant suggested that patients could be given an information pack by secondary care, which would include a checklist with topics to discuss with their GP if needed:

'I think would be helped by the sort of packs I was talking about, because as you say, nobody retains most of what they hear in the consultation when they're frightened etcetera, they've got something they can take home, then they can look at that and they can then say "I don't really understand that, I'll ask the GP about it", but I don't know that we can take up the whole remit of covering all their needs.' (practice 3, GP partner)

In addition to a lack of communication with secondary care, and other commonly mentioned barriers, such as time constraints and lack of communication with secondary care that the patients also picked up on, the primary care teams also referred to patient variability in terms of both illness history and personality:

'... of course it depends on the cancer, melanoma's very different from having secondary colonic cancer, the connotations are very different.' (practice 1, GP partner)

'And it depends on the understanding of the patient; some people are more knowledgeable, some people perhaps are in denial, for me that depends on the patient who walks through.' (practice 3 , practice nurse)

Primary care teams also highlighted that different expectations about initiation of cancer consultations posed a barrier to successful communication between them and their patients. GPs and nurses felt that an 'open door policy' was sufficient, or that they were under too much pressure to second-guess patients' wishes adequately so that the onus lay with the patient to get in touch:

'We're trying to be proactive, I think a lot of the time we end up being reactive to a lot of things, and I think it does depend therefore on how much effort they make themselves to quite an extent.' (practice 3, GP partner)

\section{DISCUSSION}

\section{Summary of main findings}

The majority of patients in this study could not recall any specific discussion of their cancer care having taken place, despite practice records indicating a review had been conducted. Most patients felt they could contact their GPs if needed, but time pressures on the GPs, a possible lack of expertise, and a perceived lack of communication with secondary care 
were seen as barriers to consulting on issues related to their cancer. GP acknowledgement of their diagnosis and treatment was important to patients. Most patients would welcome a formal cancer care review as a specific stand-alone appointment to discuss their cancer, and felt it would legitimise raising concerns. As well as acknowledgment and support, patients would like more information on clinical and supportive care issues. Most thought the optimal time for a cancer care review was at completion of initial treatment, but some would like proactive contact from the practice soon after diagnosis.

Most primary care team members saw cancer care as a clear part of their role, although a few seemed reluctant to increase their involvement. Currently there are no clear guidelines in place for the process or content of the cancer care review. In all participating practices GPs currently conducted the reviews. Primary care teams expressed uncertainty regarding the optimal timing for the review, and concern that they may not be able to provide the depth and breadth of information patients would like. They also saw the current template for the cancer care review as unhelpful, and voiced concern over losing the individualised and personalised aspects of primary care if the review became too structured.

\section{Strengths and limitations of the study}

This study adds to a growing evidence base regarding the role of primary care in the care of patients with cancer. Its strengths include participation of both patients and primary care teams, the number and diversity of patients interviewed, and the number and range of primary care team members included in the focus groups. The in-depth, qualitative nature of the study is a strength in terms of giving an insight into the way cancer care reviews are implemented and experienced, but this is an exploratory study, not based on a random sample, and results cannot be

\section{Box 1. Recommendations resulting from this study.}

GP practices may want to consider routinely contacting newly diagnosed cancer patients (either by letter or phone) at the time of diagnosis, inviting further contact if needed. This would address patients' desire for acknowledgment of their diagnosis. An invitation to a specific review appointment following completion of active treatment would promote continuity of care and legitimise the raising of any concerns. This invitation could be extended to include close family members. Primary healthcare professionals need to be supported in their role by having access to clear and up-to-date information, and rapid access to specialists if required. generalised to the primary care population. Practical and resource constraints meant that focus group methodology could not be exploited to its full extent in this study. Focus groups were conducted within timeconfined practice meetings, and included participants who know each other, and stand in hierarchical positions to each other, within a single focus group, which is sometimes seen as problematic. However, discussing the findings from interviews in practicespecific (rather than profession-specific) focus groups meant that practice teams could discuss the merits of the findings for their own practice setting.

\section{Comparison with existing literature}

Only a small number of studies have discussed patients' and healthcare professionals' views on primary care involvement in cancer care. Previous UK studies have focused on specific groups of cancer patients either in terms of cancer site (for example, breast or lung cancer, ${ }^{6,15}$ ), cancer stage (for example, advanced cancer $^{3,16}$ ), or age (for example, young adults $\left.{ }^{5,17}\right)$. The findings of this study are consistent with those of the above more narrowly defined studies, most notably in relation to the views of both GPs and patients that communication between primary care and secondary care needs to be improved..$^{5,6,15,17}$ International studies have described similar findings. ${ }^{8,18-20}$ An earlier survey by some of the authors called for more systematic implementation of cancer care reviews. ${ }^{21}$ The findings from this study lend further support to this call.

\section{Recommendations for clinical practice and future research}

The QOF aims to facilitate the delivery of high-quality care and reward good practice. ${ }^{22}$ Patient experience is a new indicator in the QOF, and is becoming increasingly important. The present study suggests that currently the cancer care component of the QOF is not delivering its promise of improving patient outcomes. Several improvements can be suggested (Box 1). Primary care practitioners may be anxious about the increased workload, but the average GP will have only around eight new cancer patients per year, and the offer of support may reap benefits in reducing patient anxiety, and improving patient confidence and satisfaction with primary care. Greater involvement of the practice and district nursing teams may also be a way to distribute the workload, and simultaneously include family members in the care.

Improved communication with secondary care is crucial to the success of primary care provision of cancer care. This should be facilitated by the introduction of survivorship care plans, currently being pilot tested by the National Cancer Survivorship Initiative. ${ }^{23}$ Relevant and clear information and 
education resources for primary healthcare professionals are also important, as is rapid access to specialists when required.

With increasing numbers of people living with cancer, and the resulting pressure in secondary care, more patients will be discharged to primary care for follow-up, and earlier than previously. Improving cancer care reviews to the satisfaction of both patients and primary care teams is therefore crucial. This exploratory study has provided some important new evidence regarding current practice and the use of cancer care reviews in primary care. Further research is needed to inform the development of primary care interventions that will improve the quality of care provided to cancer patients and their families.

\section{Funding body}

We gratefully acknowledge Macmillan Cancer Support for funding this study. Beyond funding the work underlying this article, Macmillan Cancer Support played no role in study design; in the collection, analysis, and interpretation of data; in the writing of the report; or in the decision to submit the article for publication. All authors are independent of the funder.

\section{Ethics committee}

The study received ethical approval from the Oxford Brookes University Research Ethics Committee, and from the Oxfordshire Research Ethics Committee B (Application 08/H0605/112).

\section{Competing interests}

The authors have stated that there are none.

\section{Acknowledgements}

We would like to thank Mr Bill Savage, Mr John Belcher, and Ms Annette Rauf, the user representatives on the study. They have made an invaluable contribution to all aspects of the study. We would also like to thank members of the Macmillan Palliative and Cancer Care Research Collaborative (MacPaCC) who have provided helpful comments on the study. Eila Watson is a member of MacPaCC. We would also like to thank all patients, family members and primary care teams who willingly and generously gave their time.

\section{Discuss this article}

Contribute and read comments about this article on the Discussion Forum: http://www.rcgp.org.uk/bjgp-discuss

\section{REFERENCES}

1. Department of Health. Cancer reform strategy. London: Department of Health, 2007.

http://www.dh.gov.uk/en/Publicationsandstatistics/Publications/Public ationsPolicyAndGuidance/DH_081006 (accessed 4 Mar 2011).

2. Campbell N, MacLeod U, Weller D. Primary care oncology: essential if high quality cancer care is to be achieved for all. Fam Pract 2002; 19(6): 577-578.

3. Kendall M, Boyd K, Campbell C, et al. How do people with cancer wish to be cared for in primary care? Serial discussion groups of patients and carers. Fam Pract 2006; 23(6): 644-650.
4. Cancer Action Team. Holistic common assessment of supportive and palliative care needs for adults with cancer: assessment guidance. London: Cancer Action Team, department of health, 2007. http://www.dh.gov.uk/en/Publicationsandstatistics/Publications/Public ationsPolicyAndGuidance/DH_076928?PageOperation=email (accessed 4 Mar 2011).

5. Greenfield DM, Absolom K, Eiser C, et al. Follow-up care for cancer survivors: the views of clinicians. Br J Cancer 2009; 101(4): 568-574.

6. Jiwa M, Thompson J, Coleman R, Reed M. Breast cancer follow-up: could primary care be the right venue? Curr Med Res Opin 2006; 22(4): 625-630.

7. Anvik T, Holtedahl KA, Mikalsen $\mathrm{H}$. 'When patients have cancer, they stop seeing me': the role of the general practitioner in early follow-up of patients with cancer - a qualitative study. BMC Fam Pract 2006; 7: 19

8. Kantsiper M, McDonald E, Geller G, et al. Transitioning to breast cancer survivorship: perspectives of patients, cancer specialists, and primary care providers. J Gen Intern Med 2009; 24 Suppl 2: 459-466.

9. National Gold Standards Framework Centre. The Gold Standards Framework. http://www.goldstandardsframework.nhs.uk/ (accessed 26 Oct 2010).

10. Department of Health. New GMS Contract QOF implementation: dataset and business rules - cancer indicator set. London: Department of Health, 2009.

http://www.pcc.nhs.uk/uploads/QOF/Business\%20Rules\%20v14/cance r_ruleset_v14_0.pdf (accessed 11 Mar 2011).

11. National Primary Care Development Centre. The Quality and Outcomes Framework (QOF) of the General Medical Services Contract for Primary Care: final report for cancer indicators - 2008/9 contract. Manchester: National Primary Care Development Centre, 2007. 12. Marshall C, Rossman GB. Designing qualitative research. 4 th edn. London: Sage, 2006

13. Ritchie J, Spencer L. Qualitative data analysis for applied policy research. In: Bryman A, Burgess RG (eds). Analyzing qualitative data. London: Routledge, 1994: 173-194.

14. Braun V, Clarke V. Using thematic analysis in psychology. Qual Res Psychol 2006; 3(2): 77-101.

15. Krishnasamy M, Wells M, Wilkie E. Patients and carer experiences of care provision after a diagnosis of lung cancer in Scotland. Support Care Cancer 2007; 15(3): 327-332.

16. Murray SA, Boyd K, Campbell C, et al. Implementing a service users' framework for cancer care in primary care: an action research study. Fam Pract 2008; 25(2): 78-85.

17. Absolom K, Eiser C, Michel G, et al. Follow-up care for cancer survivors: views of the younger adult. Br J Cancer 2009; 101(4): 561-567.

18. Hall SE, Holman CD, Threlfall T, et al. Lung cancer: an exploration of patient and general practitioner perspectives on the realities of care in rural Western Australia. Aust J Rural Health 2008; 16(6): 355-362.

19. Mao JJ, Bowman MA, Stricker CT, et al. Delivery of survivorship care by primary care physicians: the perspective of breast cancer patients. $J$ Clin Oncol 2009; 27(6): 933-938.

20. Nissen M, Beran M, Lee M, et al. Views of primary care providers on follow-up care of cancer patients. Fam Med 2007; 39(7): 477-482.

21. Watson E, Sugden E, Rose P. Views of primary care physicians and oncologists on cancer follow-up initiatives in primary care: an online survey. J Cancer Surviv 2010; 4(2): 159-166.

22. The Health and Social Care Information Centre. Quality and Outcomes Framework. http://www.qof.ic.nhs.uk (accessed 26 Oct 2010).

23. Macmillan Cancer Support. The National Cancer Survivorship Initiative. http://www.ncsi.org.uk/ (accessed 26 Oct 2010). 